\title{
Along-trench structural variation and seismic coupling in the northern Japan subduction zone
}

\author{
Gou Fujie $^{1}$, Seiichi Miura ${ }^{1}$, Shuichi Kodaira ${ }^{1}$, Yoshiyuki Kaneda ${ }^{1}$, Masanao Shinohara ${ }^{2}$, Kimihiro Mochizuki $^{2}$, \\ Toshihiko Kanazawa ${ }^{2 *}$, Yoshio Murai ${ }^{3}$, Ryota Hino ${ }^{4}$, Toshinori Sato ${ }^{5}$, and Kenji Uehira ${ }^{6 *}$ \\ ${ }^{1}$ Institute for Research on Earth Evolution, Japan Agency for Marine-Earth Science and Technology, Yokohama, Japan \\ ${ }^{2}$ Earthquake Research Institute, University of Tokyo, Tokyo, Japan \\ ${ }^{3}$ Hokkaido University, Sapporo, Japan \\ ${ }^{4}$ Tohoku University, Sendai, Japan \\ ${ }^{5}$ Chiba University, Chiba, Japan \\ ${ }^{6}$ Kyushu University, Fukuoka, Japan
}

(Received March 12, 2012; Revised June 7, 2012; Accepted June 14, 2012; Online published March 6, 2013)

\begin{abstract}
Large destructive interplate earthquakes, such as the $2011 M_{\mathrm{w}} 9.0$ Tohoku-oki earthquake, have occurred repeatedly in the northern Japan subduction zone. The spatial distribution of large interplate earthquakes shows distinct along-trench variations, implying regional variations in interplate coupling. We conducted an extensive wide-angle seismic survey to elucidate the along-trench variation in the seismic structure of the forearc and to examine structural factors affecting the interplate coupling beneath the forearc mantle wedge. Seismic structure models derived from wide-angle traveltimes showed signi cant along-trench variation within the overlying plate. In a weakly coupled segment, (i) the sediment layer was thick and at, (ii) the forearc upper crust was extremely thin, (iii) the forearc Moho was remarkably shallow (about $5 \mathrm{~km}$ ), and (iv) the $P$-wave velocity within the forearc mantle wedge was low, whereas in the strongly coupled segments, opposite conditions were found. The good correlation between the seismic structure and the segmentation of the interplate coupling implies that variations in the forearc structure are closely related to those in the interplate coupling.
\end{abstract}

Key words: Japan trench, wide-angle seismic survey, forearc mantle interplate coupling.

\section{Introduction}

The distribution of interplate earthquakes re ects the seismic coupling along the plate interface in subduction zones (e.g. Kanamori, 1971; Kelleher et al., 1974; Ruff and Kanamori, 1980, 1983; Kato and Seno, 2003). The downdip limit of interplate earthquakes, i.e., the maximum depth of the seismically coupled zone, is where the transition from seismic (stick-slip) to aseismic (stable-sliding) behavior occurs along the plate interface, and this limit presumably correlates with transitions in mineral and physical properties along the plate interface as well (e.g., Pacheco et al., 1993; Hyndman et al., 1995; Scholz, 1998; Oleskevich et al., 1999). Therefore, before the mechanisms of seismic coupling and of earthquake generation in subduction zones can be discussed, it is important to understand the factors that determine the downdip limit of the seismically coupled zone.

In the northern Japan subduction zone, large destructive interplate earthquakes, such as the $2011 M_{\mathrm{w}} 9.0$ Tohokuoki earthquake, and numerous interplate microearthquakes

\footnotetext{
*Now at the National Research Institute for Earth Science and Disaster Prevention, Tsukuba, Japan.

Copyright (C) The Society of Geomagnetism and Earth, Planetary and Space Sciences (SGEPSS); The Seismological Society of Japan; The Volcanological Society of Japan; The Geodetic Society of Japan; The Japanese Society for Planetary Sciences; TERRAPUB

doi:10.5047/eps.2012.06.003
}

have occurred repeatedly (e.g. Igarashi et al., 2003; Yamanaka and Kikuchi, 2004; Ide et al., 2011). The spatial distribution of these interplate earthquakes shows remarkable along-trench variations, implying that along-trench variations exist in interplate coupling. We can divide this region into three segments, A, B, and C (Fig. 1), according to the distribution of large interplate earthquakes beneath the forearc mantle wedge (Seno et al., 1980; Kawakatsu and Seno, 1983; Yamanaka and Kikuchi, 2004). In segments $\mathrm{A}$ and $\mathrm{C}$, large interplate earthquakes such as the 1968 Tokachi-oki earthquake ( $M 8$ class, in segment A) and the 1978 Miyagi-oki earthquake ( $M 7.5$ class, in segment C) have occurred repeatedly beneath the forearc mantle wedge, and the downdip limit of the coseismic rupture zone is estimated to be about 50 to $60 \mathrm{~km}$. In contrast, in the central segment B, no large interplate earthquake is known to have occurred beneath the forearc mantle wedge, and the downdip limit of large interplate earthquakes, about $20 \mathrm{~km}$, approximately corresponds to the depth of the intersection of the plate interface with the forearc Moho.

The $2011 M_{\mathrm{w}} 9.0$ Tohoku-oki earthquake is the greatest interplate earthquake that has ever been observed instrumentally in the northern Japan subduction zone. Although a large number of coseismic slip distribution models for the 2011 earthquake have been proposed, almost all these models pointed out that the coseismic slip beneath the forearc mantle wedge was small in segment B but large in segment C (Fujii et al., 2011; Ide et al., 2011; Koper et al., 


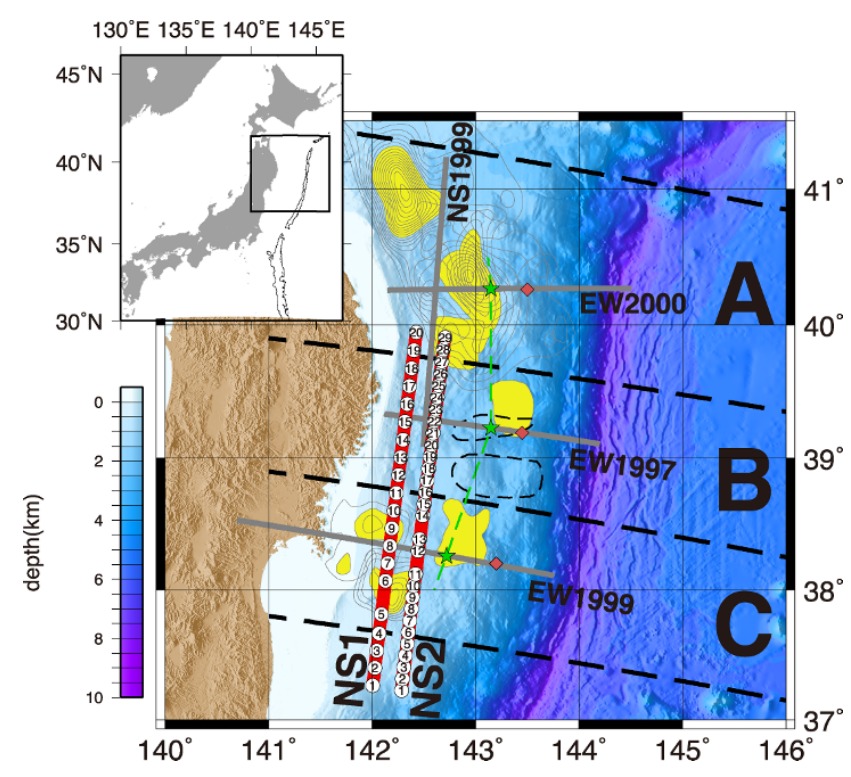

Fig. 1. Location map of wide-angle surveys in the northern Japan subduction zone. The inset map shows the location of the study area. The thick red lines labeled NS1 and NS2 are our wide-angle seismic survey transects, and the white circles on these lines represent OBSs. The thick gray lines labeled EW2000, EW1999, EW1997, and NS1999 are past wide-angle seismic survey profiles (Ito et al., 2004, 2005; Takahashi et al., 2004; Miura et al., 2005; Fujie et al., 2006). Gray contours show coseismic slip distributions of large interplate earthquakes (more than $M 7$ ) since 1930; the contour interval is $0.5 \mathrm{~m}$, and the areas with values within half the maximum slip are shaded in yellow (Yamanaka and Kikuchi, 2004). Thin dashed black curves indicate regions of low microseismicity, where a thin low-velocity layer was identified between the overlying and subducting plates (Mochizuki et al., 2005). This region has been divided into three segments, A, B, and C, based on the distribution of interplate earthquakes; thick black dashed lines mark the segment boundaries. The green stars and green dashed line show the updip (eastern) limit of the forearc mantle wedge, and red diamonds show the bending line of the subducting Pacific plate (Ito et al., 2004, 2005; Fujie et al., 2006).

2011; Ozawa et al., 2011; Simons et al., 2011; Suzuki et al., 2011). These coseismic slip distributions of M7-9 interplate earthquakes are consistent with seismic coupling models derived from geodetic studies conducted using GPS, according to which the interplate coupling beneath the forearc mantle wedge is strong in segments $\mathrm{A}$ and $\mathrm{C}$, but weak in segment B (Nishimura et al., 2004; Suwa et al., 2006).

Generally, various geophysical mechanisms can potentially affect interplate coupling beneath the forearc mantle wedge. Thermal and crustal structure studies in various subduction zones have shown that the downdip limit of the seismically coupled zone is related to temperature or to the depth of the hydrated forearc mantle wedge (Zhang and Schwartz, 1992; Tichelaar and Ruff, 1993; Hyndman et al., 1997). In warm subduction zones such as those in southwestern Japan and Cascadia, where a young, hot oceanic plate is subducting beneath a forearc, the downdip limit of large interplate earthquakes corresponds well to the depth at which the temperature reaches about $350{ }^{\circ} \mathrm{C}$, which corresponds to the temperature at which thermally-activated stable sliding behavior occurs in crustal rocks (e.g., Tse and Rice, 1986; Blanpied et al., 1991, 1995). In old, cool subduction zones, such as those in northern Chile and Alaska, the downdip limit of interplate earthquakes is much shal- lower than the depth at which the temperature of $350{ }^{\circ} \mathrm{C}$ is observed, but approximately corresponds to the intersection of the plate interface with the forearc Moho (e.g. Oleskevich et al., 1999). Hyndman and Peacock (2003) pointed out that because dry mantle rocks should be much stronger than crustal rocks, interplate earthquakes would be expected to occur at a considerable depth beneath a dry forearc mantle wedge. In contrast, a wet forearc mantle wedge, which contains a high percentage of aseismic hydrous minerals, such as serpentine and talc, should exhibit stable sliding behavior (Hyndman and Peacock, 2003). They therefore suggested that the downdip limit in these cool subduction zones could be explained by a high degree of hydration within the forearc mantle wedge.

The northern Japan trench region is a subduction zone where the old, cool Pacific plate is subducting westward beneath the northeastern Japan arc at a rate of $8-9 \mathrm{~cm} /$ year (DeMets et al., 1994). Many thermal studies have pointed out that the $350^{\circ} \mathrm{C}$ isothermal contour is significantly deeper than the downdip limit of interplate earthquakes (Hyndman and Peacock, 2003; Yamasaki and Seno, 2003; Iwamori, 2007). Although the exact temperature at a large depth is difficult to estimate, the temperature distribution alone cannot explain the remarkable downdip limit difference between adjacent segments, about $15 \mathrm{~km}$ in segment B and 50 $\mathrm{km}$ in the neighboring segments, because the temperature distribution should be continuous between these segments. Thus, the main factor determining the downdip limit of the interplate earthquakes in this subduction zone is presumably along-trench structural variation.

A number of seismic structure studies have revealed along-trench structural variations in this region. Tomographic velocity models derived from local earthquake data have shown that seismic velocities at the bottom of the forearc mantle wedge, i.e., just above the plate boundary, are low in the weakly coupled segment $\mathrm{B}$ and high in the neighboring segments A and C (e.g. Mishra et al., 2003; Yamamoto et al., 2006; Zhao et al., 2011). These studies suggested that the low velocity at the bottom of the forearc mantle wedge might be associated with forearc mantle hydration. Although these passive source seismic tomography studies could not constrain the details of the shallower portion of the overlying plate, an active source seismic structure study between segments A and B (profile NS1999 in Fig. 1) revealed along-trench structural variation in the shallower portion of the overlying plate (Hayakawa et al., 2002). Hayakawa et al. (2002) modeled the forearc Moho as being remarkably shallower in segment B (about $15 \mathrm{~km}$ ) than in segment A (about $20 \mathrm{~km}$ ), implying that the $P$-wave velocity not only at the bottom of the forearc mantle wedge, but in the entire forearc mantle wedge, might reflect the current interplate coupling beneath the forearc mantle wedge.

To reveal the structural differences between segments B and $\mathrm{C}$, we carried out an extensive wide-angle seismic refraction and reflection survey using Ocean Bottom Seismometers (OBSs) and airgun sources. In this paper, we present $P$-wave velocity structure models, derived by traveltime analysis techniques, that clearly show along-trench structural variations within the overlying plate. 

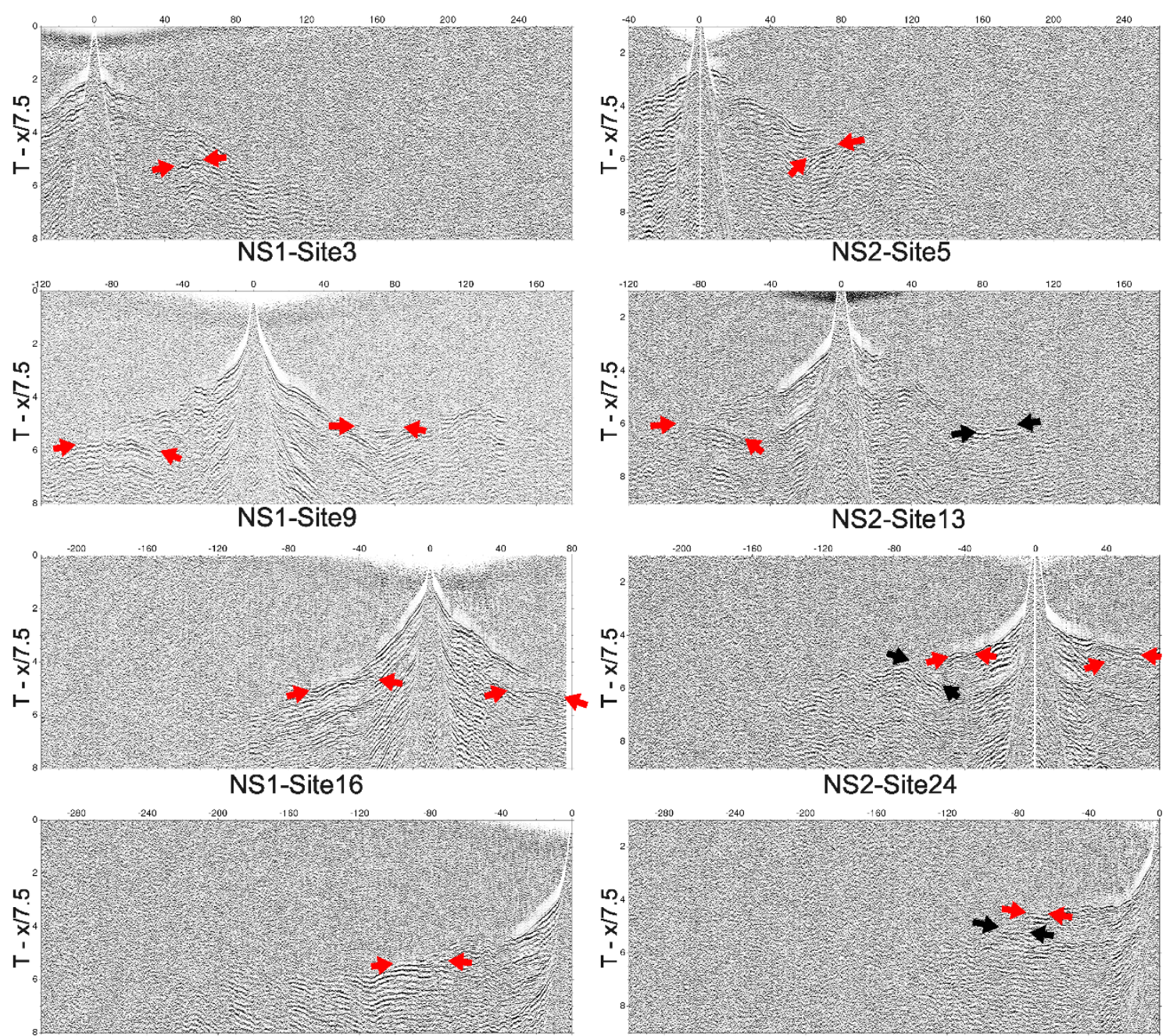

NS1-Site21

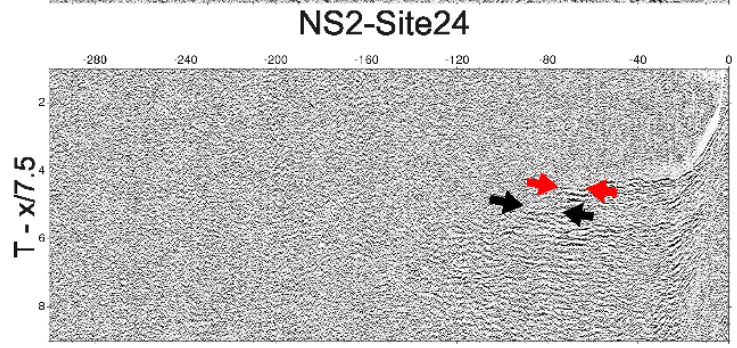

NS2-Site31

Fig. 2. Examples of observed seismic data (reduced by $7.5 \mathrm{~km} / \mathrm{s}$; a $5-20 \mathrm{~Hz}$ bandpass filter, deconvolution, and automatic gain control with a 1-s window were applied). Red arrows indicate phases that project onto the forearc Moho by traveltime mapping (Fig. 4). Black arrows indicate deeper reflections.

\section{Data and Structure Modeling}

\subsection{Description of the survey and acquired data}

To clarify the along-trench structural variation in the region where the forearc mantle wedge is in contact with the subducting Pacific plate, we established two 300-km-long transects to cover segments B and C entirely (Fig. 1). Along NS1, the landward profile, we deployed 21 OBSs at intervals of $15 \mathrm{~km}$. The water depth along profile NS1 was almost constant at about $0.5 \mathrm{~km}$. Along NS2, the trenchward profile, we deployed $31 \mathrm{OBSs}$ at intervals of $10 \mathrm{~km}$. The water depth along profile NS2 was about $1.0 \mathrm{~km}$.

Along both transects, a large airgun array (total volume 200 L), towed by R/V Kairei (Japan Agency for MarineEarth Science and Technology), was fired at 200-m intervals. During the firing, single-channel seismic (SCS) reflection data were recorded. Afterwards, all OBSs except one were recovered successfully, although two OBSs had some mechanical troubles with their recording system. Consequently, we were able to use data from 49 OBSs for our analysis.

Figure 2 shows several examples of seismic sections recorded by the OBSs. The offset ranges over which we could trace seismic signals varied among sites and phases. The most notable difference between segments B and C is the offset range in which the apparent velocity of the first arrivals reached $7.5 \mathrm{~km} / \mathrm{s}$. In segment $B$, phases with an apparent velocity of about $7.5 \mathrm{~km} / \mathrm{s}$ became first arrivals at an offset range of around $50 \mathrm{~km}$ (e.g., NS1-Site9). In segment $\mathrm{C}$, in contrast, apparent velocities of first arrivals did not reach $7.5 \mathrm{~km} / \mathrm{s}$ within an offset range of at least $80 \mathrm{~km}$ (e.g., NS1-Site3). This difference indicates that the top of the $7.5 \mathrm{~km} / \mathrm{s}$ layer is much shallower in segment B than in segment $\mathrm{C}$.

Owing to the shallow water depths, multiple reflections within the water layer (reverberations from the sea surface) with very short arrival times (about $0.5-1.5 \mathrm{~s}$, depending on the water depth of the OBS) were clearly recorded on all record sections. These multiple reflections prevented us from recognizing and picking the exact onset time of later phases. Since wrong traveltime picks generally result in wrong structure models, we did not use any of the phases that arrived after the first multiples. 


\subsection{Methods}

Our primary purpose in the structural modeling was to reveal lateral structural variation. We adopted rst arrival tomography to develop a $P$-wave velocity structure model and used the traveltime mapping method to delineate structure boundaries (Fujie et al., 2006). First arrival tomography is an objective tool for developing $P$-wave velocity structure models because rst arrivals are the least subjective phase to pick and identify, and rst arrival tomography does not require subjective layered model parameterization. However, rst arrival tomography is not suited to the determination of structural boundaries because velocity jumps are smoothed out in the resultant tomographic models.

The traveltime mapping method developed by Fujie et al. (2006) is a tool for imaging structure boundaries. This method involves the projection of traveltimes from the time-distance domain onto the depth-distance domain and is based on the same principles as diffraction-stack type prestack depth migration. After projecting a large number of traveltime data, re ectors can be imaged automatically without any phase identi cation. This is an advantage of the traveltime mapping method because phase identi cation is a very subjective analysis procedure.

The traveltime mapping method naturally requires a migration velocity structure model to project traveltime data onto the depth-distance domain. Fujie et al. (2006) showed that rst arrival tomography results constitute a good migration velocity model for imaging lithosphere scale re ectors; re ectors are imaged in the correct position and with the correct shapes by using the tomographic velocities. For details of this method, see Fujie et al. (2006).

The combination of rst arrival tomography and traveltime mapping is effective for delineating lithosphere-scale structural variations, as con rmed by previous wide-angle seismic structure studies (e.g. Ito et al., 2004, 2005; Kodaira et al., 2004).

\subsection{Structure analysis}

Starting models are important in rst arrival tomography because the nal tomographic model heavily depends on the starting model, owing to the intrinsic nonlinearity of wideangle seismic structure modeling problems. We constructed starting models by the following steps. First, we developed a starting model for the shallow section (sedimentary layers) using the results of a tau-p analysis (Stoffa et al., 1981) and the SCS sections. Next, we updated the shallow layers, up to a depth of approximately $7 \mathrm{~km}$, by a conventional trial-and-error traveltime modeling approach using refractions and re ections of short offset data (Zelt and Smith, 1992). Then, we modeled deeper parts of the section by using the previous structural models along EW1997 and EW1999 (Ito et al., 2005; Fujie et al., 2006). Finally, we adjusted the deeper parts of the section to be laterally homogeneous in order to determine the lateral structural variations objectively from the rst arrival tomography.

Using the starting models constructed as described (Fig. 3(a) and 3(b)), we obtained nal $P$-wave velocity structure models after 10 iterations (Fig. 3(c) and 3(d)). The horizontal grid spacing was $5 \mathrm{~km}$ and the vertical grid spacing was $0.5 \mathrm{~km}$. During the iterative nonlinear inversion, the root mean square of the traveltime residuals was reduced from 381 to $58 \mathrm{~ms}$ on NS1, and from 314 to $59 \mathrm{~ms}$ on NS2.

To estimate the spatial resolution of these $P$-wave velocity structure models, we applied checkerboard resolution tests, which are commonly used for this purpose in tomographic studies. Considering our OBS spacing and the target scale of the structural variations, we adopted a checkerboard grid size of $25 \mathrm{~km}$ (horizontal) and $5 \mathrm{~km}$ (depth), and assigned positive and negative velocity perturbations of 5\% to each grid. The results of tests (Fig. 3(e) and 3(f)) showed that the checkerboard patterns were well recovered to a depth of about $20 \mathrm{~km}$ along the pro le NS1, and to a depth of about $25 \mathrm{~km}$ along NS2. The better resolution along NS2, compared with that along NS1, may be attributable to (1) our ability to observe rst arrivals over a wider offset range along NS2, and (2) the denser OBS spacing on NS2, compared with NS1.

Using these tomographic models as migration velocity models, we applied the traveltime mapping method to obtain the re ector distribution along each pro le (Fig. 3(g) and $3(\mathrm{~h}))$. To compare these re ector distributions directly with the tomographic velocity models, we superimposed the mapping results onto $P$-wave velocity models after applying a spatial lter to extract the local maximum of the mapping image (Fig. 4). We consider the re ectors indicated by dashed red lines to be imaged in the correct position and with the correct shape, because those re ectors are projected onto the well-resolved area. In contrast, the re ector indicated by the dashed green line on NS2 is not constrained at all because it is projected onto an area with no ray coverage.

\section{Seismic Structure Models \\ 3.1 Cretaceous sediments}

The northern Japan trench region is the forearc region of the northeastern Japan arc and has a long history of complex tectonic activity. One characteristic of this region is widely-distributed Cretaceous, Tertiary, and Quaternary marine sedimentary layers. An unconformity separating the Cretaceous from the Neogene sedimentary rocks is a prominent horizon observed throughout most seismic re ection pro les (e.g. von Huene et al., 1994; Tsuru et al., 2000). von Huene et al. (1982) inferred that the Paleogene rocks on the Cretaceous sediments had been uplifted by the end of the Paleogene and then subsided in the Neogene (during the opening of the Japan Sea), creating the prominent unconformity. The Cretaceous metamorphosed sedimentary rocks below the unconformity, which are considered to be the old Cretaceous forearc basin and accretionary prism (Finn, 1994), have $P$-wave velocities of $4-5.5 \mathrm{~km} / \mathrm{s}$ according to previous seismic structure studies (Ito et al., 2004, 2005; Takahashi et al., 2004).

In our $P$-wave velocity structure models (Fig. 4), we inferred that the $5.5 \mathrm{~km} / \mathrm{s}$ velocity contour was a good proxy for the bottom of the Cretaceous sedimentary layer. Based on this interpretation, the thickness of the sedimentary layers shows conspicuous along-trench variation. As a general trend, the sedimentary layers are thick and the bottom of the Cretaceous sediments is nearly at in the weakly coupled segment B. In contrast, the sedimentary layers become extremely thin in segment $\mathrm{C}$. 

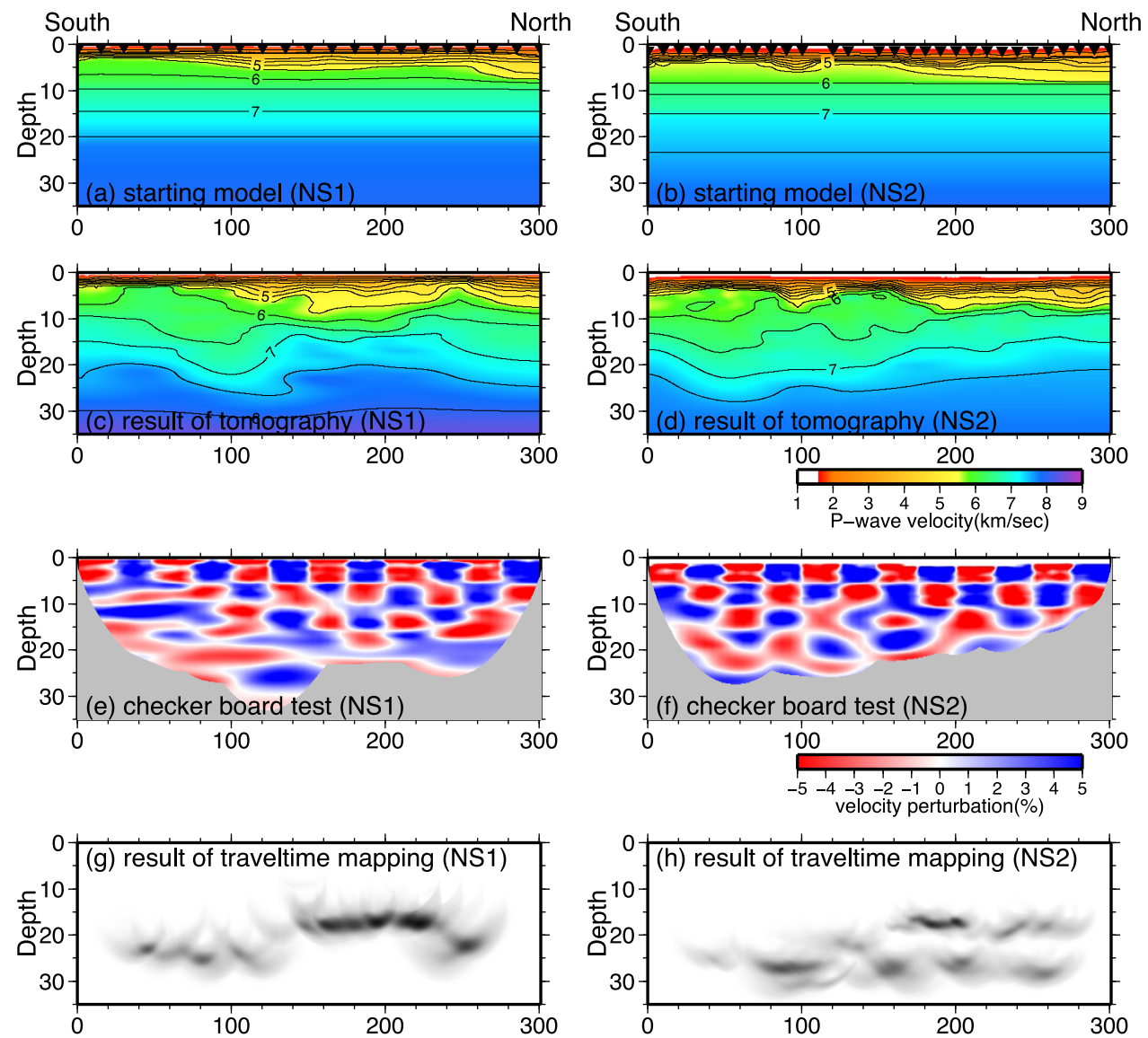

Fig. 3. Results of seismic structure modeling along profiles NS1 and NS2. (a, b) Starting models for first arrival tomography. The contour interval is $0.5 \mathrm{~km} / \mathrm{s}$, and the inverted triangles represent OBSs. The velocity node spacings for the inversion were $1 \mathrm{~km}$ (vertical) and $5 \mathrm{~km}$ (horizontal). (c, d) Final $P$-wave velocity structure models. (e, f) Results of the checkerboard resolution tests. The area with no ray coverage is shaded gray. (g, h) Reflector distributions imaged by the traveltime mapping method.
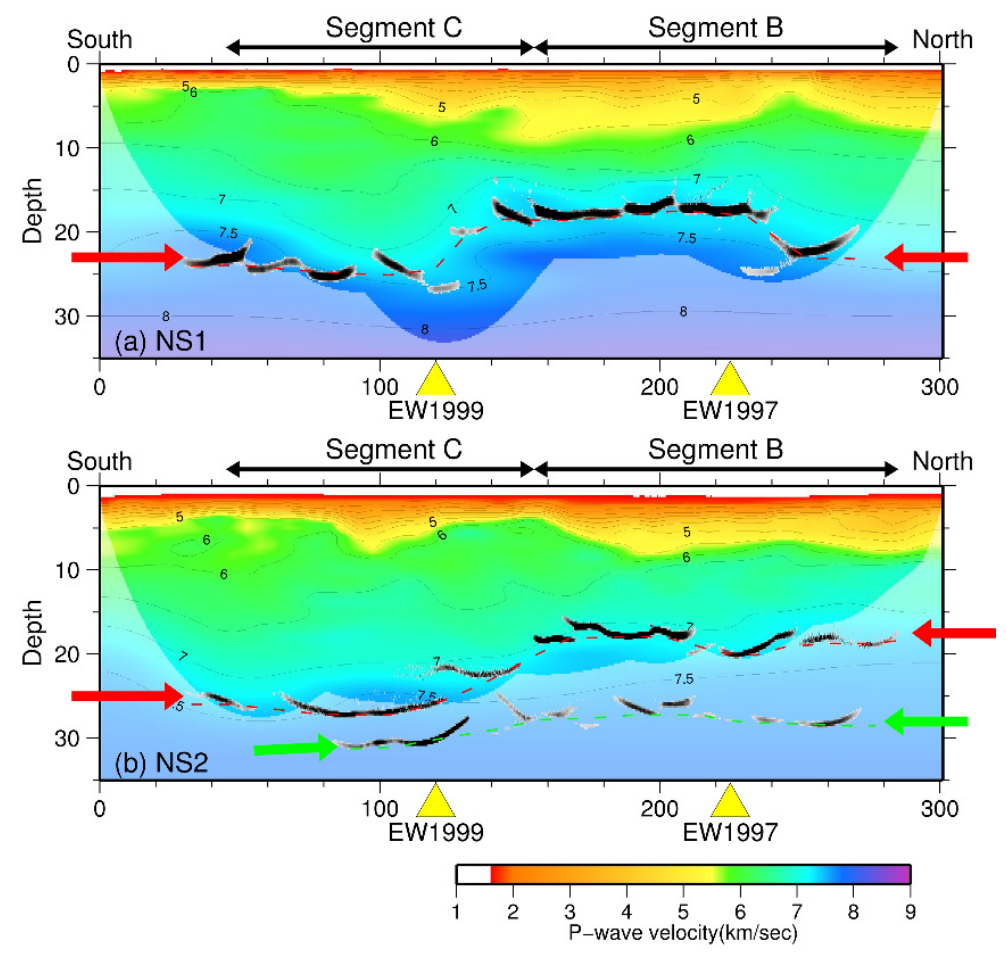

Fig. 4. $P$-wave velocity structure and reflector distributions along (a) NS1 and (b) NS2. The reflector distributions were superimposed on the velocity models after applying a spatial filter to extract the local maximum of the traveltime mapping image. Red contours represent the $7.5 \mathrm{~km} / \mathrm{s}$ velocity contour. Shaded areas indicate areas with no ray coverage in the first arrival tomography. Reflectors indicated by dashed red lines (a, b) are interpreted as the forearc Moho, and the reflector indicated by the dashed green line (b) is interpreted as the plate interface. 


\subsection{Forearc crust and forearc Moho}

As expected from the apparent velocity distribution of the rst arrivals (Fig. 2), the top of the high-velocity medium (> $7.5 \mathrm{~km} / \mathrm{s}$ ) shows signi cant along-trench variations, being shallow in segment B and deep in segment C (Fig. 4). We interpret the re ectors that are subparallel to the $7.5 \mathrm{~km} / \mathrm{s}$ velocity contour (Fig. 4, dashed red lines) as the top of the high-velocity layer. In light of our tomographic velocities and the previously-developed structural models for pro les EW2000, EW1997, and EW1999 (Ito et al., 2004, 2005; Miura et al., 2005; Fujie et al., 2006), we interpret this highvelocity layer as the forearc mantle wedge and the re ectors indicated by the dashed red lines as the forearc Moho.

The layers between the sediments and the forearc Moho are interpreted as the forearc crust. The thickness of the forearc crust shows remarkable along-trench variation, from about $10 \mathrm{~km}$ in segment $\mathrm{B}$ and to about $20 \mathrm{~km}$ in segment C.

In summary, our models show for the rst time a remarkable structural difference between segments B and C: (i) the sediments, especially the Cretaceous sediments, are thick and nearly at in segment $\mathrm{B}$, and thin and undulating in segment $\mathrm{C}$; (ii) the thickness of the forearc crust is remarkably thinner in segment $\mathrm{B}$ than in segment $\mathrm{C}$; and (iii) the depth of the forearc Moho varies markedly from shallow in segment $\mathrm{B}$ to deep in segment $\mathrm{C}$.

Hayakawa et al. (2002) identi ed similar structural differences between segments A and B by a wide-angle seismic structure study along pro le NS1999. They showed that (i) the sedimentary layers were thicker in segment B than in segment A, (ii) the forearc crust was thinner in segment B than in segment A, and (iii) the forearc Moho was remarkably shallower in segment $B$ than in segment A.

\section{3 $P$-wave velocity within the forearc mantle wedge}

Seismic velocities within the forearc mantle wedge are important for estimating the degree of mantle hydration. The $P$-wave velocities in the topmost mantle wedge are constrained by the results of the checkerboard resolution tests (Fig. 4). Our models showed that the $P$-wave velocity in the topmost mantle wedge was lower in segment B than in segment $\mathrm{C}$, but because seismic velocities around structure boundaries are generally smoothed in tomographic results, the tomographic velocities at around the depth of the topmost mantle wedge are not exact mantle velocities but the average of the velocities in the bottom of the lower crust and the top of the mantle wedge.

To quantitatively estimate the lateral variation of the $P$ wave velocities within the topmost mantle wedge, we assumed that the $P$-wave was laterally uniform at the bottom of the forearc lower crust $(7.0 \mathrm{~km} / \mathrm{s}$, Takahashi et al., 2004; Miura et al., 2005), and that the tomographic velocities at the depth of the forearc Moho were the average of the velocities at the bottom of the lower crust and the top of the mantle wedge. Along pro le NS1, we projected the forearc Moho where the tomographically-derived velocity was about $7.3 \mathrm{~km} / \mathrm{s}$ in segment B, and where it was about 7.5 $\mathrm{km} / \mathrm{s}$ in segment $C$. In accordance with the assumption of lateral uniformity, we estimated the $P$-wave velocity of the topmost mantle wedge to be about $7.5 \mathrm{~km} / \mathrm{s}$ in segment B and $8.0 \mathrm{~km} / \mathrm{s}$ in segment C. Similarly along pro le NS2, we projected the forearc Moho onto where the tomographically derived velocity was about $7.1 \mathrm{~km} / \mathrm{s}$ in segment B, and onto where it was about $7.5 \mathrm{~km} / \mathrm{s}$ in segment $\mathrm{C}$, which means that the $P$-wave velocity of the topmost mantle wedge was about $7.2 \mathrm{~km} / \mathrm{s}$ in segment B and about $8.0 \mathrm{~km} / \mathrm{s}$ in segment C.

These estimation results are well consistent with the model of Hayakawa et al. (2002) along pro le NS1999, in which the $P$-wave velocity in the topmost mantle wedge in segment $B$ was $7.3 \mathrm{~km} / \mathrm{s}$, although their ray coverage was poor.

Although these estimations include some uncertainties, it is fairly certain that the $P$-wave velocity in the topmost forearc mantle wedge in segment $B$ is lower than that in segment C. Moreover, passive-source seismic structure studies (e.g. Mishra et al., 2003; Yamamoto et al., 2006; Zhao et al., 2011) have shown that the $P$-wave velocities at the bottom of the forearc mantle wedge are low in segment B and high in segments A and C. Therefore, we infer that the $P$ wave velocity of the entire forearc mantle is lower in segment $\mathrm{B}$ than in the neighboring segments.

\subsection{Plate interface}

Seismic structure at the depth of the plate interface provides important information for understanding the occurrence of interplate earthquakes. In NS1, we could not image any re ectors below the forearc Moho, probably because of the great depth of the plate interface. In NS2, re ectors were imaged below the forearc Moho in the northern half of pro le (dashed green line in Fig. 4(b)). We interpret these re ectors as the plate interface. This interpretation is consistent with the ndings of previous structural studies along the east-west pro les EW1997 and EW1999 (Ito et al., 2005; Miura et al., 2005; Fujie et al., 2006).

In the southern half of NS2, we could not clearly image re ectors below the forearc Moho, probably because the depth difference between the forearc Moho and the plate interface is too small for them to be discriminated; the updip limit of the forearc mantle wedge is considered to be close to pro le NS2 in segment C, as shown in Fig. 1.

In any case, we cannot estimate the precise depth, and cannot describe the detailed undulations, of the plate interface because the $P$-wave velocities at this depth were not constrained at all. Before we can discuss the geometry and physical properties of the plate interface, we need to obtain data by using more powerful seismic sources.

\section{Discussion}

We have revealed the along-trench seismic structure variation within the overlying plate by wide-angle seismic traveltime analysis. Our models showed the following remarkable structural differences between segments B and C: (i) the sedimentary layers are thick in the weakly coupled segment B, but thin in the strongly coupled segment C; (ii) the forearc upper crust is extremely thin in segment $\mathrm{B}$; and (iii) the forearc Moho is much shallower in segment B than in segment C. In addition, our models showed that (iv) the $P$-wave velocity within the topmost forearc mantle wedge is low in segment $\mathrm{B}$, but high in segment $\mathrm{C}$. These results, together with those of 3-D tomographic models derived by using the data of local earthquakes (e.g., Zhao et al., 2011), 


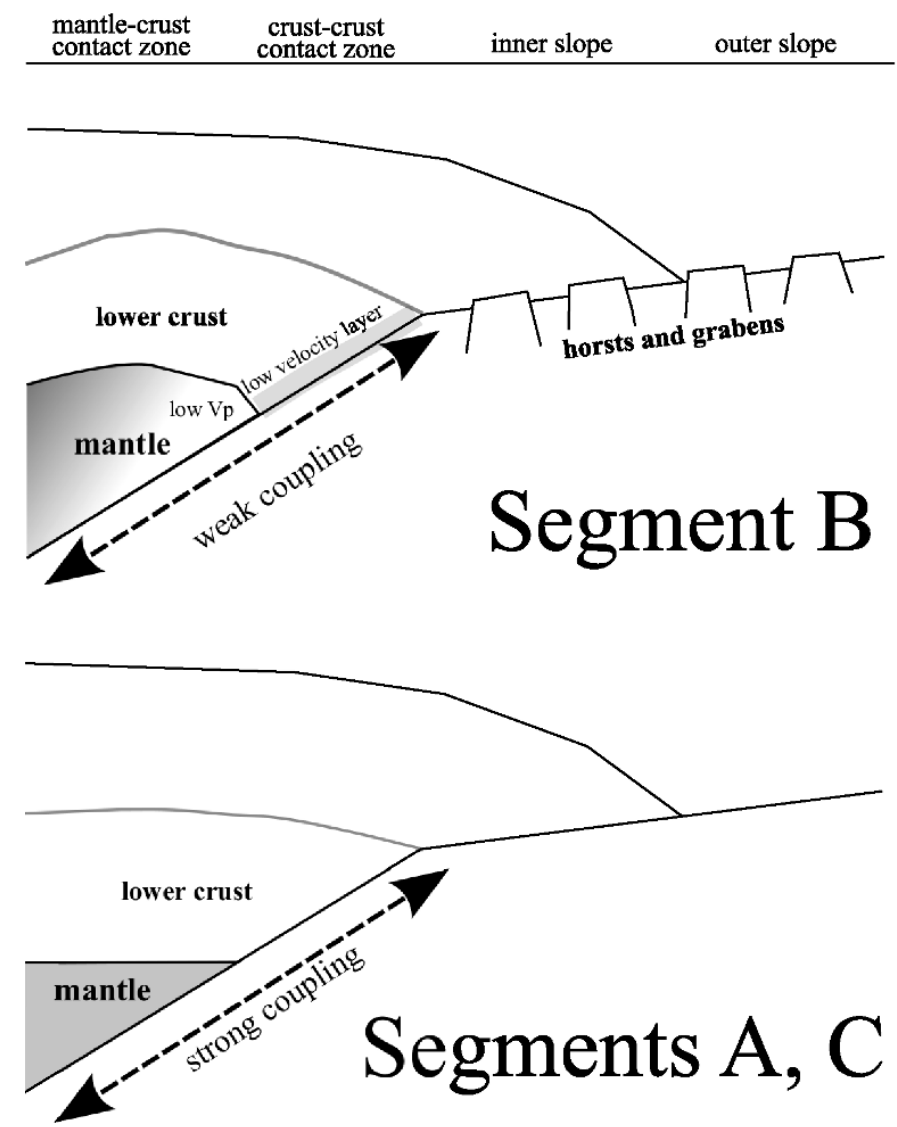

Fig. 5. Schematic cross-sections of the northern Japan subduction zone, comparing the weakly coupled segment B with strongly coupled segments A and C. Segment B has the following features, which contrast with those of segments A and C: (i) a well-developed horst and graben structure on the outer slope and beneath the inner slope; (ii) a thin layer with low $P$-wave velocity along the plate interface in the crust-crust contact zone; (iii) a shallow forearc Moho; and (iv) probably low seismic velocities within the forearc mantle wedge.

indicate that the entire overlying plate in segment $\mathrm{B}$, from the sedimentary layers to the bottom of the forearc mantle wedge, is completely different from that in the neighboring segments.

The good correlation between the along-trench variation of the forearc structure and the along-trench variation of the interplate coupling indicates that the current interplate coupling is closely related to the tectonic history since at least the Cretaceous, and that it is possibly affected by the forearc structural variation.

The variation in the forearc mantle seismic velocity suggests a corresponding variation in the degree of mantle serpentinization. According to the relation between $P$-wave velocity and the degree of serpentinization of mantle peridotites (Hyndman and Peacock, 2003), the high-velocity forearc mantle wedge in segment $\mathrm{C}$, about $8.0 \mathrm{~km} / \mathrm{s}$, indicates that the degree of serpentinization is almost $0 \%$. In contrast, the low-velocity mantle wedge in segment B, 7.2$7.5 \mathrm{~km} / \mathrm{s}$, indicates about $20 \%$ serpentinization. These estimations also contain some uncertainties, but the relative difference in $P$-wave velocities and, consequently, the degree of serpentinization is reliable.

Comparison of pro les NS1 and NS2 showed that the forearc mantle velocity of segment B was lower in pro le NS2 (about $7.2 \mathrm{~km} / \mathrm{s}$ ) than in pro le NS1 (about $7.5 \mathrm{~km} / \mathrm{s}$ ), implying that the degree of serpentinization becomes higher toward the east. Since a highly-serpentinized forearc mantle wedge should exhibit stable sliding behavior, we infer that the along-trench variation in the interplate coupling beneath the forearc mantle wedge is mainly controlled by the degree of serpentinization within the forearc mantle wedge.

A high degree of forearc mantle serpentinization suggests that a large amount of water has been supplied to the forearc mantle. In the northern Japan subduction zone, water is thought to be expelled from the subducting Paci c plate to the overlying plate by dehydration associated with the blueschist to lawsonite-eclogite reaction at the depth range of roughly 15-75 km (Okamoto and Maruyama, 1999; Yamasaki and Seno, 2003). We hypothesized that alongtrench variation of the water supply controls the alongtrench variation of the forearc mantle serpentinization. To check the validity of this hypothesis, we examined the structural differences between segment B and neighboring segments from the outer trench wall to the forearc mantle wedge, focusing on variations of water content (Fig. 5).

Beneath the outer trench wall, horst and graben structures are observed in all the segments. However, as pointed out by Tanioka et al. (1997), the sea oor roughness varies among segments and the horst and graben structures are more well-developed in segment B than in adjacent segments. Horst and graben structures are thought to develop as a result of recurring normal fault-type earthquakes such as the 1933 Sanriku earthquake, which might have ruptured the entire lithosphere (Kanamori, 1971). Thus, the well- 
developed horst and graben structure suggests active normal faulting within the incoming plate. Such well-developed normal faults should enhance the penetration of water into the incoming plate, leading to a high degree of crustal hydration (Ranero et al., 2003; Faccenda et al., 2009), and these observations thus suggest that crustal hydration within the incoming plate is higher in segment B than in neighboring segments.

In the crust-crust contact zone (depth range roughly $15-$ $20 \mathrm{~km}$ ), where the forearc crust is in contact with the subducting Paci c plate, Fujie et al. (2002) and Mochizuki et al. (2005) identi ed a thin layer with low $P$-wave velocity in a narrow region of low microseismicity between the overriding and subducting plates in segment B (Fig. 1). They suggested that candidate materials for this thin layer are aqueous uids and/or hydrated minerals such as serpentinegroup minerals, which is well consistent with our hypothesis that the water content in segment B is high.

The more water that subducts within the incoming plate, the more water that will be released by dewatering and dehydration at depth. Accordingly, we infer that the amount of water supplied to the forearc mantle wedge is larger in segment $\mathrm{B}$ than in neighboring segments, resulting in a high degree of serpentinization within the forearc mantle wedge and presumably weakening the interplate coupling in segment B.

Our speculation is that along-trench variations of water content in the incoming oceanic plate determines the degree of serpentinization within the forearc mantle and affects the regional variation of the interplate coupling in subduction zones. Therefore, structural studies of the incoming plate, in addition to the studies of the overriding plate, are essential to understand interplate coupling in subduction zones.

\section{Conclusions}

We conducted an extensive wide-angle seismic survey in the subduction zone of the northern Japan trench to reveal along-trench structural variations and their relationship to interplate coupling beneath the forearc mantle wedge.

We determined seismic structure models by using rst arrival tomography and traveltime mapping. The resulting seismic structure models showed remarkable along-trench variation within the overlying plate, from the sediment layers to the forearc mantle wedge: (i) the sedimentary layers are thick in the weakly coupled segment $\mathrm{B}$, but thin in the strongly coupled segment $C$; (ii) the forearc upper crust is extremely thin in segment B; (iii) the forearc Moho is much shallower in segment $B$ than in segment $C$; and (iv) $P$-wave velocity in the topmost forearc mantle wedge is low in segment B but high in segment $\mathrm{C}$. The good correlation between the seismic structure and segmentation of the interplate coupling implies that the variations in the forearc structure are closely related to those in the interplate coupling.

The low-velocity forearc mantle in the weakly coupled segment B suggests a high degree of serpentinization within the forearc mantle. A high degree of serpentinization in the weakly coupled segment is consistent with weak interplate coupling because serpentine minerals generally exhibit stable sliding aseismic behavior.
Structural features of the incoming plate suggest that the water content within the incoming plate is high in the weakly coupled segment B. The more water that subducts within the incoming plate, the more water which is released to the overriding plate by dehydration at depth, which implies that the water content (degree of hydration) within the incoming plate is a key factor controlling along-trench variations of interplate coupling, and, moreover, that it is essential to reveal structural variations in the incoming plate to understand the occurrence and manner of segmentation of large interplate earthquakes in subduction zones.

Acknowledgments. We thank Greg Moore and an anonymous reviewer for their thorough reviews and very helpful comments that greatly improved our manuscript. This study was partly funded by the Ministry of Education, Culture, Sports, Science and Technology as "A Pilot study on the Miyagi-ken oki earthquake".

\section{References}

Blanpied, M., D. Lockner, and J. Byerlee, Fault stability inferred from granite sliding experiments at hydrothermal conditions, Geophys. Res. Lett., 18(4), 609-612, 1991.

Blanpied, M., D. Lockner, and J. Byerlee, Frictional slip of granite at hydrothermal conditions, J. Geophys. Res., 100, 13045, 2005

DeMets, C., R. G. Gordon, D. F. Argus, and S. Stein, Effect of recent revisions to the geomagnetic reversal timescale on estimates of current plate motions, Geophys. Res. Lett., 21(20), 2191-2194, 1994.

Faccenda, M., T. Gerya, and L. Burlini, Deep slab hydration induced by bending-related variations in tectonic pressure, Nat. Geosci., 2(11), 790-793, 2009

Finn, C., Aeromagnetic evidence for a buried Early Cretaceous magmatic arc, northeast Japan, J. Geophys. Res., 99(B11), 22,167-22,185, 1994.

Fujie, G., J. Kasahara, R. Hino, T. Sato, M. Shinohara, and K. Suyehiro, A signi cant relation between seismic activities and re ection intensities in the Japan trench region, Geophys. Res. Lett., 29(7), 1100 doi:10.1029/2001GL013764, 2002.

Fujie, G., A. Ito, S. Kodaira, N. Takahashi, and Y. Kaneda, Con rming sharp bending of the Paci c plate in the northern Japan trench subduction zone by applying a traveltime mapping method, Phys. Earth Planet. Inter., 157(1-2), 72-85, 2006.

Fujii, Y., K. Satake, S. Sakai, M. Shinohara, and T. Kanazawa, Tsunami source of the 2011 off the Paci c coast of Tohoku Earthquake, Earth Planets Space, 63, 815-820, 2011.

Hayakawa, T., J. Kasahara, R. Hino, T. Sato, M. Shinohara, A. Kamimura, M. Nishino, T. Sato, and T. Kanazawa, Heterogeneous structure across the source regions of the 1968 Tokachi-oki and the 1994 Sanrikuharuka-oki earthquakes at the Japan trench revealed by an ocean bottom seismic survey, Phys. Earth Planet. Inter., 132, 89-104, 2002.

Hyndman, R. D. and S. M. Peacock, Serpentinization of the forearc mantle, Earth Planet. Sci. Lett., 212, 417-432, 2003.

Hyndman, R. D., K. Wang, and M. Yamano, Thermal constraints on the seismogenic portion of the southeastern Japan subduction thrust, J. Geophys. Res., 100(B8), 15,373-15,392, 1995.

Hyndman, R. D., M. Yamano, and D. A. Loseskevich, The seismogenic zone of subduction thrust faults, Island Arc, 6, 244-260, 1997.

Ide, S., A. Baltay, and G. Beroza, Shallow dynamic overshoot and energetic deep rupture in the $2011 \mathrm{Mw} 9.0$ Tohoku-Oki earthquake, Science, 332(6036), 1426, 2011.

Igarashi, T., T. Matsuzawa, and A. Hasegawa, Repeating earthquakes and interplate aseismic slip in the northeastern Japan subduction zone, $J$. Geophys. Res., 108(B5), 2249, doi:10.1029/2002JB001920, 2003.

Ito, A., G. Fujie, T. Tsuru, S. Kodaira, A. Nakanishi, and Y. Kaneda, Fault plane geometry in the source region of the 1994 Sanriku-oki earthquake, Earth Planet. Sci. Lett., 223, 163-175, 2004.

Ito, A., G. Fujie, S. Miura, S. Kodaira, Y. Kaneda, and R. Hino, Bending of the subducting oceanic plate and its implication for rupture propagation of large interplate earthquakes off Miyagi, Japan, in the Japan trench subduction zone, Geophys. Res. Lett., 32(5), L05310, doi:10.1029/2004GL022307, 2005.

Iwamori, H., Transportation of $\mathrm{H} 2 \mathrm{O}$ beneath the Japan arcs and its implications for global water circulation, Chem. Geol., 239(3-4), 182-198, 2007. 
Kanamori, H., Seismological evidence for a lithospheric normal faulting the Sanriku earthquake of 1933, Phys. Earth Planet. Inter., 4, 289-300, 1971.

Kato, N. and T. Seno, Hypocenter depths of large interplate eathquakes and their relation to seismic coupling, Earth Planet. Sci. Lett., 210, 53-63, 2003.

Kawakatsu, H. and T. Seno, Triple seismic zone and the regional variation of seismicity along the northern Honshu arc, J. Geophys. Res., 88, 42154230, 1983.

Kelleher, J., J. Savino, H. Rowlett, and W. McCann, Why and where great thrust earthquakes occur along island arcs, J. Geophys. Res., 79(32), 4889-4899, 1974.

Kodaira, S., T. Iidaka, A. Kato, J.-O. Park, T. Iwasaki, and Y. Kaneda, High pore uid pressure may cause silent slip in the Nankai trough, Science, 304, 1295-1298, 2004.

Koper, K. D., A. R. Hutko, T. Lay, C. J. Ammon, and H. Kanamori, Frequency-dependent rupture process of the $2011 \mathrm{Mw} 9.0$ Tohoku Earthquake: Comparison of short-period $\mathrm{p}$ wave backprojection images and broadband seismic rupture models, Earth Planets Space, 63, 599$602,2011$.

Mishra, O. P., D. Zhao, N. Umino, and A. Hasegawa, Tomography of northeast Japan forearc and its implications for interplate seismic coupling, Geophys. Res. Lett., 30(16), 1850, doi:10.1029/2003GL017736, 2003.

Miura, S., N. Takahashi, A. Nakanishi, T. Tsuru, S. Kodaira, and Y. Kaneda, Structural characteristics off Miyagi forearc region, the Japan trench seismogenic zone, deduced from a wide-angle re ection and refraction study, Tectonophysics, 407, 165-188, 2005.

Mochizuki, K. et al., Intense PP re ection beneath the aseismic forearc slope of the Japan Trench subduction zone and its implication of aseismic slip subduction, J. Geophys. Res., 110, B01302, doi:10.1029/2003JB002892, 2005.

Nishimura, T., T. Hirasawa, S. Miyazaki, T. Sagiya, T. Tada, S. Miura, and K. Tanaka, Temporal change of interplate coupling in northeastern Japan during 1995-2002 estimated from continuous gps observations, Geophys. J. Int., 157(2), 901-916, 2004.

Okamoto, K. and S. Maruyama, The high-pressure synthesis of lawsonite in the morb+h2o system, Am. Mineral., 84, 362-373, 1999.

Oleskevich, D. A., R. D. Hyndman, and K. Wang, The updip and downdip limits to great subduction earthquakes: Thermal and structural models of Cascadia, south Alaska, SW Japan, and Chile, J. Geophys. Res., 104(B7), 14,965-14,991, 1999.

Ozawa, S., T. Nishimura, H. Suito, T. Kobayashi, M. Tobita, and T. Imakiire, Coseismic and postseismic slip of the 2011 magnitude- 9 tohoku-oki earthquake, Nature, doi:10.1038/nature10227, 2011.

Pacheco, J., L. Sykes, and C. Scholz, Nature of seismic coupling along simple plate boundaries of the subduction type, J. Geophys. Res., 98(B8), 14,133-14,159, 1993.

Ranero, C. R., J. P. Morgan, K. Mcintosh, and C. Reichert, Bending-related faulting and mantle serpentinization at the Middle America trench, $\mathrm{Na}$ ture, 425, 367-373, 2003.

Ruff, L. and H. Kanamori, Seismicity and the subduction process, Phys. Earth Planet. Inter., 23(3), 240-252, doi:10.1016/0031-9201(80)90117X, 1980.

Ruff, L. and H. Kanamori, Seismic coupling and uncoupling at subduction zones, Tectonophysics, 99, 99-117, 1983.

Scholz, C., Earthquakes and friction laws, Nature, 391(6662), 37-42, doi: 10.1038/34097, 1998.

Seno, T., K. Shimazaki, P. Somerville, K. Sudo, and T. Eguchi, Rupture process of the Miyagi-oki, Japan, earthquake of June 12, 1978, Phys.
Earth Planet. Inter., 23, 39-61, 1980.

Simons, M. et al., The 2011 Magnitude 9.0 Tohoku-Oki earthquake: Mosaicking the megathrust from seconds to centuries, Science, 332(6036), 1421, 2011.

Stoffa, P., P. Buhl, J. Diebold, and F. Wenzel, Direct mapping of seismic data to the domain of intercept time and ray-parameter-a plane-wave decomposition, Geophysics, 46(3), 255-267, 1981.

Suwa, Y., S. Miura, A. Hasegawa, T. Sato, and K. Tachibana, Interplate coupling beneath NE Japan inferred from three-dimensional displacement eld, J. Geophys. Res., 111, B04402, doi:10.1029/2004JB003203, 2006.

Suzuki, W., S. Aoi, H. Sekiguchi, and T. Kunugi, Rupture process of the 2011 Tohoku-Oki mega-thrust earthquake (M9.0) inverted from strongmotion data, Geophys. Res. Lett., 38, doi:10.1029/2011GL049136, 2011.

Takahashi, N. et al., Seismic structure and seismogenesis off Sanriku region, northeastern Japan, Geophys. J. Int., 159(1), 129-145, 2004.

Tanioka, Y., L. Ruff, and K. Satake, What controls the lateral variation of large earthquake occurrence along the Japan Trench?, Island Arc, 6, 261-266, 1997.

Tichelaar, B. and L. Ruff, Depth of seismic coupling along subduction zones, J. Geophys. Res., 98(B2), 2017-2037, 1993.

Tse, S. and J. Rice, Crustal earthquake instability in relation to the depth variation of frictional slip properties, J. Geophys. Res., 91(B9), 94529472, 1986.

Tsuru, T., J.-O. Park, N. Takahashi, S. Kodaira, Y. Kido, Y. Kaneda, and Y. Kono, Tectonic features of the Japan trench convergent margin off Sanriku, northeastern Japan, revealed by multichannel seismic re ection data, J. Geophys. Res., 105(B7), 16,403-16,413, 2000.

von Huene, R., M. Langseth, N. Nasu, and H. Okada, A summary of Cenozoic tectonic history along the IPOD Japan Trench transect, Geol. Soc. Am. Bull., 93(9), 829, 1982.

von Huene, R., D. Klaeschen, B. Cropp, and J. Miller, Tectonic structure across the accretionary and erosinal parts of the Japan trench margin, $J$. Geophys. Res., 99, 22,349-22,361, 1994.

Yamamoto, Y., R. Hino, M. Nishino, T. Yamada, T. Kanazawa, T. Hashimoto, and G. Aoki, Three-dimensional seismic velocity structure around the focal area of the 1978 Miyagi-Oki earthquake, Geophys. Res. Lett., 33, L10308, doi:10.1029/2005GL025619, 2006.

Yamanaka, Y. and M. Kikuchi, Asperity map along the subduction zone in northeastern Japan inferred from regional seismic data, J. Geophys. Res., 109, B07307, doi:10.1029/2003JB002683, 2004.

Yamasaki, T. and T. Seno, Double seismic zone and dehydration embrittlement, J. Geophys. Res., 108(B4), 2212, doi:10.1029/2002JB001918, 2003.

Zelt, C. A. and R. B. Smith, Seismic traveltime inversion for 2-d crustal velocity structure, Geophys. J. Int., 108, 16-34, 1992.

Zhang, Z. and S. Schwartz, Depth distribution of moment release in underthrusting earthquakes at subduction zones, J. Geophys. Res, 97, 537544, 1992.

Zhao, D., Z. Huang, N. Umino, A. Hasegawa, and H. Kanamori, Structural heterogeneity in the megathrust zone and mechanism of the 2011 Tohoku-oki earthquake (Mw 9.0), Geophys. Res. Lett., 38, doi:10.1029/2011GL048408, 2011.

G. Fujie (e-mail: fujie@jamstec.go.jp), S. Miura, S. Kodaira, Y. Kaneda, M. Shinohara, K. Mochizuki, T. Kanazawa, Y. Murai, R. Hino, T. Sato, and K. Uehira 